\title{
Algumas reflexões sobre as novas techologias da comunicação e informação e a importância da Crítica Genética
}

\section{Resumo}

Este artigo apresenta uma breve reflexão sobre as influências das novas tecnologias da informação e da comunicação e, simultaneamente, traz a Crítica Genética para essa discussão. A intenção não é assumir uma posição de defesa ou de crítica com relação ao uso e influência dos meios de comunicação. Porém, apontar a Crítica Genética como uma área de estudos e pesquisa que nos ajuda a repensar essa influência. É Cecília Almeida Salles (1997/1998) quem nos apresenta um amplo estudo sobre a Crítica Genética. Para Salles, o objetivo da Crítica Genética está voltado para o processo criativo.

Como é criada uma obra? Esta é a sua questão principal. A Crítica Genética vê a obra a partir da sua construção. É um campo de estudos em que se pesquisa a produção da obra segundo os rastros deixados por quem a produziu. $\bigcirc$ foco de atenção é, portanto, o processo: entender a construção da obra e sua produção. Por que conhecer estudos realizados pela Crítica Genética nos ajuda a repensar as novas tecnologias da informação e comunicação? Esta é uma questão que tentarei responder neste artigo.

\section{Abstract}

This article presents a brief reflection on the influences of information and communication new technologies añd, simultaneously, it conduces this discussion to the Genetic Criticism. The proposal isn't to assume a defensive posture or a critical attitude related to the use and influence of the mass communication.
Cecilia Almeida Salles (1997-1998) presents to us a comprehensive study about Genetic Criticism tumed to " the creative process.

How a masterpiece is created? This is the main question. The Genetic Criticism sees the work of art by its construction process. It's a field of studies in which one researches the work of art production according the marks left by whom has produced it. The focus is then the process: to understand the construction of the piece and its production. Why acquainting studies carried out by Genetic Criticism help us to rethink about the information and communication new technologies? This text tries to answer this question.

Vivemos um tempo de mudanças e transformações drásticas, uma revolução proveniente das novas tecnologias da informação e da comunicação: uma revolução caracterizada pelo desenvolvimento das telecomunicações, da informática, da automação dos serviços, dos satélites, da internet etc. Diante de tantas modificações, é impossível fazer de conta que a nossa forma de ser e de pensar não sejam influenciadas por elas.

As transformações que estão surgindo nos modos de produção da comunicação têm exigido novas maneiras de recepção; trabalhar essa nova recepção significa aprender novas formas de ver, interpretar, interagir e compreender a realidade. "A educação na sociedade da informação deve basear-se na utilização de habilidades comunicativas, de tal modo que nos permita participar mais ativamente e de forma mais crítica e reflexiva da sociedade". (IMBERNÓN, 1999, p.31).

Por vivermos em um mundo mediático ${ }^{1}$, é importante que saibamos enfrentar e decifrar essas

\footnotetext{
* Doutoranda em Comunicação e Semiótica - PUC/SP. Mestre em Educação: Didática. Professora do curso de Pedagogia das Faculdades Integradas "Campos Salles".

${ }^{1}$ Sociedade mediática: sociedade impregnada pelos meios de comunicação.
} 
novas formas de mensagens/linguagens que chegam até nós. Fazemos parte de um contexto informatizado e tecnológico; logo, a escola não pode ficar alheia às outras linguagens, além da verbal, sendo um espaço para a interação dessas novas linguagens.

Como professora de Didática em cursos de Pedagogia e preocupada com a formação de meus alunos, tenho me perguntado: com todas as transformações que estão ocorrendo em nossa sociedade (no mundo da produção, do trabalho e da comunicação/informação), será que tenho trazido para a sala de aula o significado dessas mudanças?

Creio ser difícil pensar na escola e no discurso pedagógico sem refletir sobre as diferentes formas atuais de comunicação. Portanto, já que estamos vivendo em contextos multilingüísticos, repletos de linguagens diversas, poderíamos nos preparar para compreender criticamente o que elas podem significar.

Assim, pretendo fazer uma pequena reflexão sobre as influências dessas novas formas de comunicação/informação e trazer a Crítica Genética para essa discussão. Como mote para iniciá-la, recorro ao texto Tela Total, de Baudrillard (1997, p. 145):

Vídeo, tela interativa, multimídia, Internet, realidade virtual: a interatividade nos ameaça de toda parte. Por tudo, mistura-se o que era separado; por tudo, a distância é abolida: entre os sexos, entre os pólos opostos, entre o palco e a platéia, entre os protagonistas da ação, entre o sujeito e o objeto, entre o real e o seu duplo. Essa confusão dos termos e essa colisão dos pólos fazem com que em mais nenhum lugar haja a possibilidade do juízo do valor: nem em arte, nem em moral, nem em política. Pela abolição da distância, do "pathos da distância", tudo se torna irrefutável... Por toda parte onde opera essa promiscuidade, essa colisão dos pólos, há massificação.

Algo que, a meu ver, merece um aprofundamento é o fato de não termos condições físicas e psíquicas de refletirmos, de olharmos o que está sendo mostrado, apresentado. Quando afirmo que não temos condições físicas, refiro-me à ausência de um espaço físico, de um necessário distanciamento para pensar. Quando somos expostos a algo, quando recebemos uma informação, às vezes é preciso um certo distanciamento para analisar o conteúdo que nos foi mostrado. Logo, se eu não posso me distanciar, me isolar, também não posso refletir, pensar, aprofundar e, por sua vez, construir relações.

Quando supomos que telespectador e autor ocupam o mesmo espaço, ou constituem "a mesma imagem", corremos o risco de não analisar os fatos que estão sendo mostrados. Sem distanciamento não é possível olhar e, sem olhar/escutar é também impossível pensar, analisar. Ser ator ou ser espectador depende desse distanciamento, dessas possibilidades de afastamento, de lugares a serem assumidos.

Para Baudrillard, diferentemente do que ocorreu com o cinema, a fotografia e a pintura, onde percebemos uma cena e um olhar, "a imagem-vídeo, como a tela do computer, induz a uma espécie de imersão, de relação umbilical, de interação 'tátil', como já dizia McLuhan sobre televisão". (1997, p.146).

Dessa forma, o espectador e o ator ocupam o mesmo lugar e, quando todos se tornam atores, não há mais ação, fim da representação. Com a morte do espectador, temos o fim da ilusão estética.

Baudrillard vai mais longe e volta a afirmar:

que num certo nível maquinal, de imersão na máquina virtual, não há mais distinção homem/ máquina: a máquina situa-se nos dois lados da interface. Talvez não sejamos mais do que espaços pertencentes a ela - o homem transformado em realidade virtual da máquina, seu operador especular, o que corresponde à essência da tela. (1997, p.147).

Estamos imersos na maquinaria virtual; não há mais separaçã̃o entre o homem e a máquina, entre o real e o virtual.

Giroux (1997) parece compartilhar, também, dessa idéia. Segundo o autor, o desenvolvimento da ciência e tecnologia ofereceu a possibilidade de libertar o homem do trabalho exaustivo e desumano; porém, esse mesmo desenvolvimento 
introduziu formas de domínio e de controle que mais parecem opor-se às possibilidades de emancipação humana do que ampliá-las.

É dentro desse paradoxo que Giroux (1997) discute a importância e função da leitura em uma sociedade multimídia. Para tal, procura distinguir a cultura visual da cultura impressa. Para Giroux (1997), todos os modos de comunicação podem ser manipuladores. Porém, a cultura impressa é um meio que exige um pouco mais de atenção. Ela não é tão impositiva quanto a cultura visual. Quando lemos, temos mais tempo de parar e refletir sobre o que foi escrito. "Com a palavra é possivel avaliar com mais rigor a validade e valor verídico de um argumento" (p.117). A escrita cria algumas possibilidades de "afastamento". Talvez aquele mesmo distanciamento que Baudrillard enfatizou.

Com poucas possibilidades de se afastar, o telespectador, a menos que disponha de um equipamento de vídeo, que possa reduzir a velocidade ou observar novamente a cena que foi apresentada, tem poucas oportunidades de se distanciar do conteúdo da produção visual e pensar sobre o que está sendo apresentado/seu significado. (GIROUX, 1997).

Para Aronowitz, citado em Giroux (1997), pesquisas sugerem uma tendência crescente entre estudantes para:

ver as coisas de maneira literal e não conceitual; estes estudos também têm apontado para a crescente incapacidade dos estudantes de pensar dialeticamente, ver as coisas em um contexto mais amplo ou estabelecer relações entre objetos ou eventos aparentemente não relacionados. Ele e outros autores também se queixam do fato dos estudantes estarem amarrados à 'factualidade' do mundo, e parecem ter dificuldades de utilizar conceitos que poderiam controverter as aparências. (p.119).

Essas novas tecnologias da comunicação e da informação, em especial a internet e a televisão, mostram a informação de uma forma "fugaz", às vezes impactante, podendo ser até alienante e, em determinados momentos, massificante. Sinto que nos falta tempo para pensar, analisar e rela- cionar o que está sendo "despejado" por todos esses canais. E, a cada dia que passa, parece que ficam mais difíceis o distanciamento e o tempo necessários para darmos conta da complexidade do que está sendo mostrado. Enfim, construir o real que nos chega é quase impossível. Se não reestruturarmos nossa forma de pensar, buscando novos modos de expressão e de recepção, dificilmente conseguiremos dar conta de todas essas informações. Nada avançou tanto no mundo como as comunicações. É claro que esse processo não vai parar e muito menos retroceder.

É interessante observar que essas novas tecnologias também têm influenciado a arte. Em artigo publicado na Folha de S. Paulo, no dia 4 de julho de 2001, Daniela Rocha divulga a $6^{-}$ Bienal de Arte Contemporânea de Lyon, na França, afirmando que a arte hoje é multidisciplinar, interativa e tecnológica.

A proposta de trabalho dessa nova geração de artistas visuais usufrui dessa tecnologia e tem se tornado cada vez mais instantânea, virtual. O espectador é convidado a participar, a interagir. As imagens são modificadas pelo próprio público, seja na interpretação da obra, seja na intervenção direta sobre ela, recriando-as a cada segundo. Muitos dos trabalhos apresentados eram interativos, utilizando foto, vídeo e instalação. Real e imaginário estão presentes o tempo inteiro.

Minha intenção não é assumir uma posição de defesa ou de crítica com relação ao uso e influência dos meios de comunicação. Porém, sinto que é de fundamental importância repensarmos essa interatividade; talvez a Crítica Genética possa nos ajudar a entender essa complexidade e, o que considero mais importante, até exercitarmos uma nova recepção.

\section{Um pouco da Crítica Genética}

É Cecília Almeida Salles $(1997,1998)$ quem nos apresenta um amplo estudo sobre a Crítica Genética. Para Salles, o objetivo da Crítica Genética está voltado para o processo criativo. Como é criada uma obra? Esta é sua questão principal. A Crítica Genética vê a obra a partir da 
sua construção. É um campo de estudos em que se pesquisa a produção da obra, segundo os rastros deixados por quem a produziu. $\mathrm{O}$ foco de atenção é, portanto, o processo: entender a construção da obra e sua produção. Refaz, com o material que possui, o caminho percorrido pelo artista para chegar à obra entregue ao público, analisando os registros que foram deixados ao longo do seu percurso de criação. Porém, estudar esse percurso, o caminho assumido pelo artista, é perceber que não temos

$o$ acesso direto ao fenômeno mental que os registros materializam, mas estes podem ser considerados a forma física através da qual esse fenômeno se manifesta. Não temos, portanto, o processo de criação em mãos, mas apenas alguns indices desse processo. São vestígios vistos como testemunho material de uma criação em processo. (SALLES, 1998, p.17).

A Crítica Genética lida com um pensamento em evolução, ou seja, idéias que vão surgindo, que são selecionadas, aperfeiçoadas, combinadas, hipóteses sendo alteradas, um emaranhado de relações que vão sendo tecidas. Toda a criação na arte envolve um processo de transformação basicamente dinâmico, flexível e não-linear. Nunca uma somatória, mas uma rede de tendências que se inter-relacionam. (SALLES, 1998).

O crítico genético preocupa-se em compreender os percursos criativos, o movimento do criador, ou seja, o rumo assumido pelo artista. Salles(1998), ao buscar uma caracterização mais geral do ato criador, dentro de um contexto mais amplo, observa que a tendência do processo pode ser considerada sob dois pontos de vista: projeto poético e comunicação.

Segundo a autora, em toda prática criadora detectamos características pessoais, singulares e únicas que são próprias do artista. Essas características relacionam-se com o tempo e o espaço em que a obra foi produzida. Portanto, é afetada pelo contexto no qual o artista está inserido, ou seja, seu momento histórico, social, cultural e científico. Exemplificando esse aspecto, lembro uma fala de Manoel Bandeira citada por Salles
(1998): "Somos duplamente prisioneiros: de nós mesmos e do tempo em que vivemos" (p. 37). Assim, o crítico genético, ao desvendar o percurso de uma obra, percebe como a realidade externa influencia o que está sendo mostrado na obra.

Outro aspecto importante do projeto poético é perceber, também, que ele é permeado por princípios éticos. Quando afirmamos que a obra tem algo de pessoal, que é singular e que pertence ao artista, sua forma de representar o mundo, de dialogar com ele aparecerá na obra. Assim, o projeto ético caminha lado a lado com a intenção estética do artista: "O grande projeto vai se mostrando, desse modo, como princípios éticos e estéticos, de caráter geral, que direcionam o fazer do artista: princípios gerais que norteiam o momento singular que cada obra representa". (SALLES, 1998, p. 39).

$\mathrm{O}$ autor, ao construir sua obra, intenciona partilhá-la com outras pessoas. Sente necessidade de que ela seja vista, pensada, analisada, criticada, enfim, que ela toque de alguma maneira as pessoas que a receberem. Ao produzi-la, necessita compartilhá-la, pois o ato de criação é um ato comunicativo. (SALLES, 1998). O ato comunicativo pode ser visto considerando-se três instâncias: o aspecto comunicativo do ato criador sob o ponto de vista de suas relações culturais no tempo e no espaço, na intimidade do processo em que são travados diálogos inter/intrapessoais e o receptor da obra.

Salles (1998) levantou, em seu texto, cinco diferentes perspectivas de se discutir o ato criador, ou seja, podemos olhar para o processo de criação como: ação transformadora, movimento tradutório, processo de conhecimento, construção de verdades artísticas e percurso de experimentação. É através dessas diferentes possibilidades que temos de observar o movimento criador, que ampliamos a nossa compreensão.

O processo de criação, observado sob o ponto de vista de sua transformação, aponta os gestos criadores numa seqüência de ações que estão inter-relacionadas. "Anotações, esboços, filmes assistidos, cenas relembradas, livros anotados, tudo tem o mesmo valor para o pesquisador interessado em compreender o ato criador, e está, de algum 
modo, conectado". (SALLES, 1998, p. 88).

É importante que se perceba, ao reconstruir o processo de criação, que o artista inicialmente não tem uma seqüência estabelecida para a elaboração de sua obra. Apesar de o artista ter uma intenção, algo a ser dito, é no próprio processo que a seqüência vai sendo estabelecida.

A natureza inferencial do processo significa a destruição do ideal de começo e de fim absolutos. Para essa discussão, a ênfase recai com maior força na impossibilidade de se determinar um primeiro elo na cadeia; no entanto, a constatação de que o ato criador é uma cadeia implica, necessariamente, igual indeterminação de últimos elos. (SALLES, p.88).

Entender a criação como processo de inferências é detectar que os elementos aparentemente dispersos estão interligados, e é através da ação transformadora que percebemos como um elemento inferido acaba sendo atado.

Segundo Salles (1998), podemos perceber dois momentos transformadores especiais ao longo do processo de criação: a percepção artística e a seleção de recursos artísticos. Através dos materiais utilizados pelo artista, seus diários, anotações e correspondências, conseguimos perceber e anotar os registros da sua percepção. São informações que refletem a forma como o artista percebe o mundo e o elabora/transforma.

Desse modo, deduz-se que a criação não ocorre a partir do nada, mas utiliza o que está sendo observado/olhado pelo artista. No processo de criação, o artista estabelece elos, conexões, entre o que está sendo observado e a obra em construção. Segundo Salles (1998, p.96): "é a excitação usada pela sensibilidade da percepção que permite a continuidade do processo. Esses efeitos têm, portanto, poder gerativo: são sensações que tendem para o futuro".

Assim, podemos afirmar que o artista utiliza a realidade externa, e no processo de transformação do que está sendo absorvido dessa realidade, a memória tem papel significativo. É através dela, do que foi visto, sentido, experimentado, vivenciado, que o artista recria, refaz, reconstrói, repensa, enfim, o que é passado tornase presente e proposta de futuro. "A memória é ação. A imaginação não opera, portanto, sobre o vazio, mas com a sustentação da memória". (SALLES, 1998, p.100).

O artista, ao construir sua obra, utiliza diferentes recursos criativos. A seleção dos recursos não é feita "a priori", mas, geralmente, durante o processo. Para Salles (1998), não conseguimos discutir os meios utilizados pelo artista sem pensar no que está sendo produzido. Quando o artista escolhe determinados materiais, ele o faz supondo algo que quer construir. Logo, há uma relação dialética entre forma e conteúdo, o que impossibilita uma discussão separada desses elementos.

$\mathrm{O}$ projeto poético proposto pelo artista sofre transformações provenientes dos recursos que estão sendo utilizados. Durante o percurso criativo, o artista experimenta diferentes caminhos, constrói diversas possibilidades, porém algumas são selecionadas em vez de outras. Assim, ao mesmo tempo que elabora sua obra, o artista pensa, reflete e gera conhecimento. "O processo de criação, como processo de experimentação no tempo, mostra-se, assim, uma permanente e vasta apreensão de conhecimento". (SALLES, 1998, p.156).

O ato criativo é, portanto, construção de conhecimento em que o experimentar acontece o tempo todo. Por ser processo, o que interessa é trabalhar na continuidade, sem a pretensão de se chegar ao fim. Ao percorrer diferentes processos de criação, nota-se um contínuo movimento tradutório - tradução intersemiótica, ou seja, a tradução de uma linguagem por outra. $\mathrm{O}$ artista utiliza diferentes linguagens "que vão durante $o$ processo recebendo diferentes tratamentos e desempenhando diferentes funções e, assim, emerge outro instante de unicidade dos processos". (SALLES, 1998, p.121). Não obstante o percurso de criação ser intersemiótico, quando o artista finaliza uma obra, geralmente tenta mostrá-la utilizando uma determinada linguagem. Assim, nos documentos do processo de criação são encontradas diferentes linguagens, pois o ato criador é de natureza híbrida.

Finalizando essa breve explicação do que é a Crítica Genética, Salles $(1997,1998)$ aponta para 
a riqueza das pesquisas genéticas a serem realizadas em outras áreas de conhecimento, porém sem deixar de aproveitar o que tem sido encontrado no processo de criação artística. $\mathrm{O}$ crítico genético, ao percorrer o processo de criação, desvenda uma mente em criação e os mecanismos utilizados pelo artista ao produzir uma obra. Trazer essas preocupações para outras áreas de conhecimento poderá nos ajudar a entender um pouco mais os nossos processos cognitivos, o que para a educação tem sido uma questão fundamental.

A seguir, levanto alguns aspectos que apontam a importância da Crítica Genética e das novas tecnologias da educação e informação.

\section{A Crítica Genética e as novas \\ tecnologias da educação e comunicação: algumas relações}

\section{O que a Crítica Genética parece mostrar é} que construir uma obra é algo trabalhoso, que exige esforço, determinação; é um projeto a ser alcançado, algo a ser dito. Quem tem o privilégio de estudar as "pegadas" do criador, perceberá, ao reconstruí-las, uma evolução de pensamento, assim como distinguirá diferentes linguagens utilizadas em seu projeto.

Considero importante a possibilidade de exercitar a evolução de um pensamento. No curso de Pedagogia/Didática, ao lidar com a formação do professor, poderíamos estudar conteúdos que discutem os processos de produção e criação de uma obra, pois ao realizar esse trabalho estaríamos exercitando um olhar diferenciado para a cultura. Determinadas experiências da Crítica Genética parecem ser um campo de estudo que exercita as nossas recepções e, já que vivemos num contexto multilingüístico e somos influenciados por diferentes linguagens, aprender a interagir com elas parece ser necessário.

A Crítica Genética possibilita um salto crucial, uma vez que pode reeducar o nosso olhar e propiciar uma recepção mais crítica das novas tecnologias da comunicação e informação. Oferecer uma nova possibilidade de ler, receber uma obra e trabalhar essa recepção crítica é dos seus aspectos mais valiosos, fundamentalmente por vivermos um tempo de rápidas mudanças.

Mudança, transformação, rapidez, velocidade, informação: palavras de ordem na sociedade atual. Todas implicam profundas alterações em praticamente todos os segmentos da nossa sociedade e acabam afetando a nossa maneira de ser, de pensar e, principalmente, de perceber. Assim, parece importante que saibamos enfrentar e decifrar as formas de mensagens/linguagens que chegam até nós, e a escola não pode ficar alheia a essa multiplicidade.

Torna-se importante propiciar condições para que o aluno perceba o que é um processo de criação, as ações que permeiam tal percurso e as diferentes linguagens que fazem parte do que está sendo construído. Essa alternativa de trabalho contribuiria para uma melhor percepção de mundo. Conhecer a construção de uma obra e estudar as "pegadas" deixadas pelo artista nos faz compreender o que pode ser um processo de criação. $\mathrm{O}$ artista, ao construir sua obra, planeja, pesquisa, experimenta, constrói conhecimento; essas ações não são inatas ou divinas, mas provenientes do trabalho de alguém que está disposto a pensar e a realizar algo.

Pensar, ação difícil de ser realizada, principalmente no momento atual, em que tudo é tão veloz, simultâneo e, aparentemente, fácil. Parece que a tecnologia carrega consigo a palavra "facilidade". Em meio a toda essa facilidade, a ação de pensar poderia ser considerada supérflua?

A Crítica Genética mostra que fazer algo, ter um projeto artístico, não é fácil e pensar não é uma ação superficial, exige do artista determinação, dedicação, esforço, pesquisa, reflexão, experimentação e, sobretudo, que o ser humano tenha consciência de que é um ser inacabado. Mostra, também, que estamos sempre experimentando: "um processo que fica sempre por se completar, um desejo que fica por ser totalmente satisfeito". (SALLES, 1998, p.31).

Viver incomodado com a sensação de que algo pode ser feito, que precisa ser feito é que nos faz "humanos", gente. E como dizia Mário de 
Andrade, citado por Cecília Salles (1998, p.30):

"A arte é uma doença, é uma insatisfação humana e o artista combate a doença fazendo mais arte, outra arte. Fazer outra arte é a única receita para a doença estética da imperfeição".
Seria de interesse para o curso de Pedagogia acompanhar estudos realizados na Crítica Genética, assim como "exercitar" pesquisas já realizadas. Seriam formas de exercício de pensamento para uma relação mais harmoniosa e construtiva com as novas tecnologias.

\section{REFERÊNCIAS BIBLIOGRÁFICAS}

BAUDRILLARD, Jean. Tela total. Porto Alegre: Sulina, 1997.

GIROUX, Henry A. A cultura de massa e o surgimento do novo analfabetismo: implicações para a leitura. In: Os professores como intelectuais. Porto Alegre: Artes Médicas, 1997.

IMBERNÓN, Francisco. A educação no século XXI. Porto Alegre: Artes Médicas, 2000.

ROCHA, Daniela. Curadores extrapolam limites da arte em Lyon. Folha de São Paulo. Caderno Ilustrada, 4 jul. 2001.

SALLES, Cecília Almeida. Crítica genética. São Paulo: EDUC, 1997.

. Gesto inacabado. São Paulo: Annablume, 1998. 